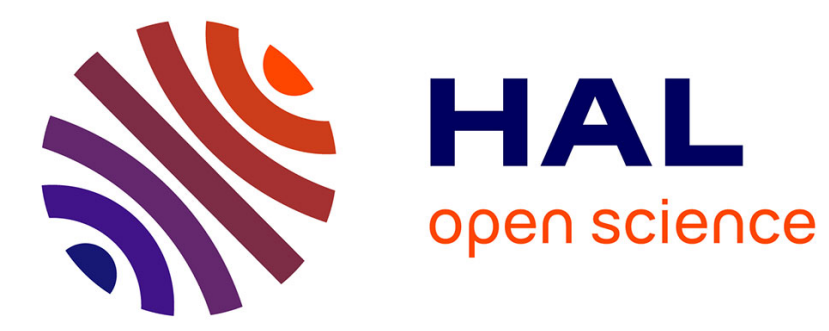

\title{
A framework for the system-of-systems analysis of the risk for a safety-critical plant exposed to external events \\ Enrico Zio, Elisa Ferrario
}

\section{To cite this version:}

Enrico Zio, Elisa Ferrario. A framework for the system-of-systems analysis of the risk for a safetycritical plant exposed to external events. Reliability Engineering and System Safety, 2013, 114, pp.114125. 10.1016/j.ress.2013.01.005 . hal-00803169

\section{HAL Id: hal-00803169 \\ https://hal-centralesupelec.archives-ouvertes.fr/hal-00803169}

Submitted on 21 Mar 2013

HAL is a multi-disciplinary open access archive for the deposit and dissemination of scientific research documents, whether they are published or not. The documents may come from teaching and research institutions in France or abroad, or from public or private research centers.
L'archive ouverte pluridisciplinaire HAL, est destinée au dépôt et à la diffusion de documents scientifiques de niveau recherche, publiés ou non, émanant des établissements d'enseignement et de recherche français ou étrangers, des laboratoires publics ou privés. 


\title{
A framework for the system-of-systems analysis of the risk for a safety-critical plant exposed to external events.
}

\author{
E. Zio ${ }^{a, b}$ and E. Ferrario ${ }^{a}$ \\ ${ }^{a}$ Chair on Systems Science and the Energetic Challenge, European Foundation for New Energy - Electricité de \\ France, at École Centrale Paris - Supelec, France \\ enrico.zio@ecp.fr, enrico.zio@supelec.fr \\ ${ }^{b}$ Department of Energy, Politecnico di Milano, Italy \\ enrico.zio@polimi.it
}

\begin{abstract}
We consider a critical plant exposed to risk from external events. We propose an original framework of analysis, which extends the boundaries of the study to the interdependent infrastructures which support the plant. For the purpose of clearly illustrating the conceptual framework of system-of-systems analysis, we work out a case study of seismic risk for a nuclear power plant embedded in the connected power and water distribution, and transportation networks which support its operation. The technical details of the systems considered (including the nuclear power plant) are highly simplified, in order to preserve the purpose of illustrating the conceptual, methodological framework of analysis. Yet, as an example of the approaches that can be used to perform the analysis within the proposed framework, we consider the Muir Web as system analysis tool to build the system-of-systems model and Monte Carlo simulation for the quantitative evaluation of the model. The numerical exercise, albeit performed on a simplified case study, serves the purpose of showing the opportunity of accounting for the contribution of the interdependent infrastructure systems to the safety of a critical plant. This is relevant as it can lead to considerations with respect to the decision making related to safety critical-issues.
\end{abstract}

Keywords: External Events Risk Analysis, System of Systems, Muir Web, Monte Carlo Simulation, Seismic Probabilistic Risk Assessment. 


\section{INTRODUCTION}

The focus of this work is to look at the safety of a critical plant challenged by the occurrence of an external event, like earthquake, flooding, high wind, fire, lightning, volcanic eruption [1]. We assume that properly designed and dimensioned, "internal" emergency devices are available to assure safety of the critical plant upon such disturbances, even in the case of unavailability of the infrastructure services. However, accidental events in the industrial history, e.g., the recent Fukushima disaster [2], show that the post-accident assurance of the full or partial safety of a critical plant in the emergency conditions of an external disastrous event may also need to resort to exceptional recovery means and actions, which need to be supported by the infrastructures connected to the critical plant. In other words, upon the occurrence of the destructive event, the surrounding environment may or may not be left in the conditions to provide "emergency assistance" to the critical plant. Indeed, considering an external event which is spatially distributed, its impact may not affect only the critical plant itself but also the areas around it, with possible damages to the interdependent infrastructures that may or may not be capable of providing the services needed for keeping or restoring the safety of the critical plant.

With these considerations, we propose to extend the boundaries of the analysis for evaluating its safety by adopting a "system-of-systems" framework of analysis [3], [4], [5], [6], [7], [8], [9] which includes the interdependent infrastructures connected to the plant, in addition to its internal emergency devices, and thus examines also the "resilience" properties offered from the overall structure of the system of systems in which the plant is embedded. For the purpose of illustrating the concepts underlying the extended framework, as quantitative indicator we consider the probability that a critical plant remains or not in a "safe state" upon the occurrence of an external event. Safe state is here used to indicate that the plant is in a condition that does not cause health and/or environmental damages.

To provide an example of application of the proposed framework, we consider a case study regarding the occurrence of an earthquake (the external event) impacting on a system of systems which contains a nuclear power plant (the critical plant) that is provided with the needed emergency infrastructure systems. For exemplary purposes, the framework extends the analysis to the power and water distribution, and to the transportation networks (the interdependent infrastructure systems) that can provide services necessary for keeping or restoring the safety of the critical plant. The case study is used only to illustrate the concepts behind the framework of analysis under a system-of-systems viewpoint: for this reason, it is 
fictitious and admittedly highly simplified in the technical aspects (including those of the nuclear power plant and its safety systems) and strong, possibly at times not too realistic, assumptions are made to keep the focus on the methodological framework. In spite of this, for completeness the modeling and numerical evaluation are carried out by resorting to powerful methods of system analysis and stochastic simulation: Muir Web [10] and Monte Carlo simulation [11], [12], [13].

Muir Web is a system analysis technique to model a complex system and the relationships among its elements. In the context of ecological human community, in which it has been first introduced [10], traditionally only the major interactions are taken into account in the system modeling: for example, with reference to the food chain, only the connections between predator and prey are usually considered, whereas other relevant and influencing relationships exist between organisms, e.g., one species may take cover for another, and other factors contribute to the food chain, e.g., abiotic elements like water, sun, soil, rainfall, wind [10]. By the representative power of Muir Web, the traditional picture of dependencies is extended through a graph where the nodes represent all the system elements (e.g., species and abiotic factors in the ecological case) and the edges represent their dependency structure.

The concept of Muir Web has been recently applied also to infrastructure systems, exploiting some similarities which exist between the ecological and the infrastructure networks [14]: both are large scale systems with complex interactions and can fail when an external event occurs. In the case of infrastructure systems, the nodes of the web are system components, e.g., a pump, and other factors which influence the infrastructure state, e.g., a stable soil with respect to seismic hazard.

In the case study worked out in this paper, the assessment is performed in two main steps: first, a conceptual map in the form of a Muir Web is built to represent all the dependencies and interdependencies among the components of the infrastructure systems connected to the nuclear power plant; then, Monte Carlo simulation is applied to compute the probability that the nuclear power plant enters in an unsafe state, accounting for the contributions of both the internal emergency devices and the connected infrastructures to support the safety of the critical plant. An analysis is also made to find how much the interdependencies would affect the safety of the nuclear power plant.

The remainder of the paper is organized as follows. In Section 2, the basic concepts of External Event Risk Assessment are introduced, with some specifics of Seismic Probabilistic Risk Assessment (SPRA) for positioning the illustrative case study used to exemplify the methodology; in Section 3, the Monte Carlo simulation framework for SPRA is described for 
providing the basic ground of the quantification technique used in the case study; in Section 4, the complete assessment of the case study by Muir Web and Monte Carlo simulation is presented, and the results discussed; in Section 5, conclusions and reflections are shared and future developments are provided.

\section{NATURAL EXTERNAL EVENT RISK ASSESSMENT}

The framework of the analysis considers natural external events as hazard inputs. They can include earthquake, flooding, high wind, fire, lightning, volcanic eruption [1]. The common characteristics of these hazards are the large-scale impacts on the environment and the considerable amount of uncertainty related with their occurrence and their intensity.

To include them in the safety analysis of a critical plant, the following steps should be performed [1]:

a. Assessment of the frequency of the hazards (i.e., estimation of the frequency of exceedance of particular intensities) and analysis of the loads associated;

b. Analysis of the plant response to the hazards (i.e., fragilities);

c. Analysis of the impacts of the hazards on the plant.

To proceed in the analyses, properties and parameters of the hazards should be defined. For example, for seismic hazard, parameters like intensity of the earthquake, ground motion and frequency content (e.g., response spectrum) should be defined; for flooding, relevant parameters include water level of the river/lake, duration of flood and water velocity; for high winds, the dynamic loads from gusts and rotation velocities from tornadoes should be given.

In the present paper, the seismic hazard has been taken into account within a framework of Seismic Probabilistic Risk Assessment (SPRA) based on three parts [15], [16]:

a. Seismic Hazard Analysis to compute the probabilities of occurrence of different levels of earthquake ground motion at a site of interest.

b. Seismic Fragility Evaluation to identify the seismic capacity of a component in terms of its conditional probability of failure for any given ground motion level.

c. System Analysis to integrate the outputs of the hazard and fragility analyses for evaluating the impacts of the earthquake on the infrastructure of interest.

The first part, which is traditionally developed as Probabilistic Seismic Hazard Analysis (PSHA), consists of four procedural steps [15], [16], [17]: 
1) Identification and characterization of the earthquake source;

2) Definition of the earthquake recurrence relationship, i.e., the annual frequency of occurrence of a given magnitude event for each source, typically described by the Gutenberg-Richter law [18] that implies a double-truncated exponential distribution for the magnitude ${ }^{1}$ [21], [22]:

$F_{M}(m)=\frac{1-e^{-\beta\left(m-m_{\min }\right)}}{1-e^{-\beta\left(m_{\max }-m_{\min }\right)}}$

where $\beta$ represents the relative frequency of smaller to larger events and $m_{\max }$ and $m_{\min }$ are the upper and lower bounds of the magnitude, respectively, that avoid the high values which are unrealistic and the low values that are negligible.

3) Formulation of the ground motion attenuation relationship that identifies the ground motion value at the site of interest, e.g., the peak ground acceleration, given the source-to-site distance and the magnitude. The higher the distance from the source, the lower is the ground motion value. The following relationship described by Ambraseys [23] has been embraced in this paper:

$$
\begin{aligned}
& \log _{10} z^{\prime}=C_{1}+C_{2} m+\left(C_{3}+C_{4} m\right) * \log _{10} \sqrt{r^{2}+C_{5}^{2}}+C_{6} S_{S}+C_{7} S_{A}+C_{8} F_{N}+ \\
& C_{9} F_{T}+C_{10} F_{O}
\end{aligned}
$$

where $m$ is the magnitude, $r$ is the source-to-site distance, $S_{S}$ and $S_{A}$ represent the types of soil (soft, stiff or rock, when both variables are set to zero) and $F_{N}, F_{T}$ and $F_{O}$ describe the faulting mechanism (normal, thrust or odd).

4) Computation of the exceedance probability of ground motion in any time interval by an analytical integration for each magnitude, distance and ground motion value.

In the second part of the SPRA, a fragility evaluation is carried out to provide the parameter values (i.e., the median acceleration capacity $A_{m}$ and the logarithmic standard deviation due to randomness and to uncertainty in the median capacity $\beta_{r}$ and $\beta_{u}$, respectively) for the fragility model that assumes this expression [15]:

$f^{\prime}=\Phi\left[\frac{\log \left(\frac{z^{\prime}}{A_{m}}\right)+\beta_{u} \Phi^{-1}(Q)}{\beta_{r}}\right]$

where $f^{\prime}$ is the conditional probability of failure for any given ground motion level $z$ ' and $Q$ is the subjective probability of not exceeding a fragility $f$ '.

\footnotetext{
${ }^{1}$ The magnitude scale typically used is the moment magnitude defined by Kanamori [19]. For medium size earthquakes it is similar to the Richter values [20].
} 
In the third part, an evaluation of the consequences of the seismic event to the infrastructure under analysis is traditionally performed by the development of event trees and logic models for each event tree top event [15]. In this work, we adopt a Muir Web representation and Monte Carlo simulation for this evaluation.

\section{MUIR WEB REPRESENTATION AND MONTE CARLO SIMULATION FOR SEISMIC PROBABILISTIC RISK ASSESSMENT WITHIN A SYSTEM-OF-SYSTEMS FRAMEWORK}

In this Section, the objective of the Muir Web modeling is first illustrated (Section 3.1) and the Muir Web representation of a system of systems is then given (Section 3.2). Finally, the operative steps of the Monte Carlo (MC) simulation method for Seismic Probabilistic Risk Assessment (SPRA) are illustrated (Section 3.3).

\subsection{Muir Web modeling}

The Muir Web is a network representation technique, which allows analysis by graph theory. It has been introduced to explicitly represent the structure of dependence of the physical elements on factors which influence their functionalities. It is a tool to visualize, capture and understand the relations among physical elements and factors of a system, and it organizes the knowledge in a comprehensive way through its multi-dimensional structure. It is inspired by the view of John Muir, the famous naturalist [24]: "When we try to pick out anything by itself we find that it is bound fast by a thousand invisible cords that cannot be broken, to everything in the universe". The original purpose behind the introduction of the Muir Web was to recreate the landscape and the wildlife of the city of Mannahatta four hundred years ago to see how that place was before it became a city and to reimagine the city's development taking into account the natural cycles and processes [10]. For this aim, the Muir Web can be converted into maps by an iterative computer program that works through all the relationships and find the right layers in a Geographic Information System [10].

In the Muir web representation there is no difference among the types of relations: they are depicted by arrows that are directed from an element to another dependent on it. Applying it to an engineered system means to consider all the other elements (physical, operational, organizational, etc.) which each single element depends on, including, for example, the type of soil, the maintenance task, the presence of operators, etc. One main objective of the Muir 
Web is to visualize all the connections among elements. This gives the basis for performing further analysis to characterize the types of relations, the way a failure of an element can affect the state of another connected element, the elements with significant influence on the system functionality and those with little influence.

Table 1 states the advantages and limitations of the Muir Web with respect to other techniques, i.e., Fault Tree Analysis and Hierarchical modelling.

In synthesis, the Muir Web seems to offer a flexible and easy way of representation, with the possibility of managing a large number of nodes and relationships. In addition, extending the analysis to the level of factors (operational, organizational, etc.) that influence the physical elements, it shows the capability of crossing disciplinary boundaries in an integrated representation; then, it can interface straightforwardly with other modelling tools to generate maps representing the spatial localization of the infrastructures, including their interdependences and all related characteristics. This flexibility and ease of representation is paid by the large amount of information needed to further characterize the model and the need of further analyses to associate the logic structure of the system and evaluate it in terms of the quantities of interest, which may be costly simulations for large systems. 
Table 1: Comparison of the Muir Web with Fault Tree Analysis and Hierarchical modelling.

\begin{tabular}{|c|c|c|c|c|c|c|}
\hline & \multicolumn{2}{|c|}{ Muir Web } & \multicolumn{2}{|c|}{ Fault Tree Analysis } & \multicolumn{2}{|c|}{ Hierarchical modelling } \\
\hline & Advantages & Limitations & Advantages & Limitations & Advantages & Limitations \\
\hline \multirow{5}{*}{$\begin{array}{l}\text { Qualitative } \\
\text { analysis }\end{array}$} & $\begin{array}{l}\text { Representing the invisible: in } \\
\text { addition to the physical elements, } \\
\text { the representation includes the } \\
\text { factors (operational, } \\
\text { organizational, etc.) which the } \\
\text { physical elements depend on. The } \\
\text { associated knowledge is organized } \\
\text { in a comprehensive way through a } \\
\text { multi-dimensional structure. }\end{array}$ & $\begin{array}{l}\text { A large amount of } \\
\text { information and } \\
\text { competences of different } \\
\text { disciplinary fields are } \\
\text { needed to build the } \\
\text { representation. }\end{array}$ & $\begin{array}{l}\text { The physical elements are } \\
\text { represented in a well-defined } \\
\text { structure, according to the } \\
\text { logic of the system, that leads } \\
\text { to the identification of the } \\
\text { Minimal Cut Sets. }\end{array}$ & $\begin{array}{l}\text { Additional factors } \\
\text { (operational, organizational, } \\
\text { etc.) are not included. } \\
\text { The exhaustive identification } \\
\text { and manipulation of the } \\
\text { Minimal Cut Sets can be } \\
\text { difficult for large systems. }\end{array}$ & $\begin{array}{l}\text { The system is broken up } \\
\text { according to its parts and it } \\
\text { is analyzed at different } \\
\text { levels of detail. }\end{array}$ & $\begin{array}{l}\text { Additional factors } \\
\text { (operational, organizational, } \\
\text { etc.) are not included. }\end{array}$ \\
\hline & $\begin{array}{l}\text { Easy to build the network } \\
\text { answering the question "why" to } \\
\text { identify the depending elements. }\end{array}$ & & & $\begin{array}{l}\text { Difficult to build the fault } \\
\text { tree, in particular in the case } \\
\text { of large number of } \\
\text { components and complicated } \\
\text { logic, dependencies, etc. }\end{array}$ & $\begin{array}{l}\text { Easy to build the hierarchy, } \\
\text { identifying the parts of the } \\
\text { system with increasing level } \\
\text { of detail. }\end{array}$ & \\
\hline & $\begin{array}{l}\text { Extendable/Flexible: the addition } \\
\text { of a new component is possible } \\
\text { without changing all the structure. }\end{array}$ & $\begin{array}{l}\text { A further analysis is needed } \\
\text { to identify the logic } \\
\text { structure of the system. }\end{array}$ & $\begin{array}{l}\text { The structured representation } \\
\text { allows a rigorous and } \\
\text { transparent analysis. }\end{array}$ & $\begin{array}{l}\text { The addition of a new } \\
\text { component can change the } \\
\text { structure. }\end{array}$ & $\begin{array}{l}\text { Analyzing the system at } \\
\text { different levels of detail } \\
\text { allows a good understanding } \\
\text { of the system structure. }\end{array}$ & $\begin{array}{l}\text { The addition of a new } \\
\text { component can change the } \\
\text { hierarchy. }\end{array}$ \\
\hline & $\begin{array}{l}\text { The representation clearly } \\
\text { illustrates the dependencies } \\
\text { among the components: arrows } \\
\text { are directed from one element to } \\
\text { another dependent on it. In } \\
\text { addition, there is the possibility of } \\
\text { including the strength of the } \\
\text { relationship }{ }^{2} \text {. }\end{array}$ & & $\begin{array}{l}\text { The representation is clear } \\
\text { and allows understanding } \\
\text { which combinations of } \\
\text { components cause the failure } \\
\text { of the top event. The } \\
\text { modelization is } \\
\text { straightforward via few, } \\
\text { simple, logic operators. }\end{array}$ & $\begin{array}{l}\text { The Boolean-logic based } \\
\text { approach does not allow } \\
\text { considering the strength of } \\
\text { the relationships. }\end{array}$ & $\begin{array}{l}\text { The representation is clear } \\
\text { and allows understanding the } \\
\text { composition of the system at } \\
\text { different levels of detail. }\end{array}$ & $\begin{array}{l}\text { The representation does not } \\
\text { show the relationships } \\
\text { among the components at } \\
\text { each level of the hierarchy } \\
\text { and a further analysis is } \\
\text { needed for that. }\end{array}$ \\
\hline & $\begin{array}{l}\text { Possibility to be converted into } \\
\text { maps, resorting to the support of } \\
\text { Geographic Information Systems. }\end{array}$ & & & & & \\
\hline $\begin{array}{l}\text { Quantitative } \\
\text { analysis }\end{array}$ & $\begin{array}{l}\text { Simulation: propagation of } \\
\text { failures in the network. }\end{array}$ & $\begin{array}{l}\text { High computational cost of } \\
\text { simulation for large } \\
\text { systems. }\end{array}$ & $\begin{array}{l}\text { Numerical calculation of the } \\
\text { probability of occurrence of } \\
\text { the top event by transforming } \\
\text { the logical structure into an } \\
\text { equivalent probability form. }\end{array}$ & $\begin{array}{l}\text { Difficulty in treating the } \\
\text { dynamics of failures. }\end{array}$ & $\begin{array}{l}\text { Simulation: propagation of } \\
\text { failures bottom-up through } \\
\text { the hierarchy. }\end{array}$ & $\begin{array}{l}\text { High computational cost of } \\
\text { simulation for large } \\
\text { systems. }\end{array}$ \\
\hline
\end{tabular}

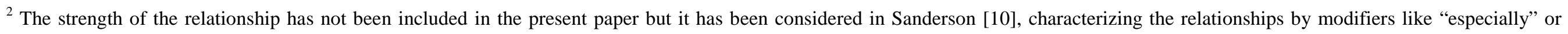
"often". 


\subsection{Muir Web representation of a system of systems}

For a general representation of the system of systems based on the Muir Web framework (Figure 1), let us consider a plant $H$ that is critical from the safety viewpoint, i.e., if it is not provided with the necessary service inputs it can reach a condition which causes health and environmental damages. The state of the critical plant $H$ is the state of its critical element, $E$. Connections exist to $N_{S}$ interdependent systems $S_{i}, i=1, \ldots, N_{S}$, numbered in order in such a way that the first $q$ are those inside the plant and the last $N_{S}-q$ belong to systems outside the plant. The systems internal to the plant $S_{i}, i=1, \ldots, q$, are designed to provide inherent safety, i.e., the input services required to keep $E$ in a safe state. Each system is composed by $N_{c_{i}}$, $i=1, \ldots, N_{S}$, components and the overall system of systems is therefore formed by $N=$ $N_{\text {in }}+N_{\text {out }}$ components, where $N_{\text {in }}=\sum_{i=1}^{q} N_{c_{i}}$ and $N_{\text {out }}=\sum_{i=q+1}^{N_{S}} N_{c_{i}}$. For the sake of clarity of the representation, we distinguish the intra-system and inter-systems links, i.e., the links among components of the same system and of different systems, respectively, into two types here called "direct dependency" and "support dependency" on the basis of their physical meaning: for the first type, when a component fails, its direct neighbors also fail; for the second one, when a component fails, it does not cause the failure of its neighbors because it assumes the role of "support", i.e., it is useful to the neighbors when these fail for other reasons. In addition, the links between the interconnected infrastructure systems and the critical plant have been considered. They represent unidirectional dependency, but if a connected system fails, it does not mean that the critical plant fails too; identification, specification and joint analysis of all these dependencies have to be performed to determine their effect on the critical plant, as explained in Section 3.3. The Muir Web of Figure 1 shows an example in which the element $E$ (star) of the critical plant $H$ (dotted-rectangular shape) is connected to four interdependent systems $S_{i}, i=1, \ldots, 4$ with $N_{c_{1}}=5, N_{c_{2}}=6, N_{c_{3}}=7$ and $N_{c_{4}}=3$ components. The systems $S_{1}$ and $S_{2}$ are inside the plant and the systems $S_{3}$ and $S_{4}$ are outside. The direct dependencies are represented by solid lines, the support ones by dashed lines and the connections to the critical plant by bold lines. 


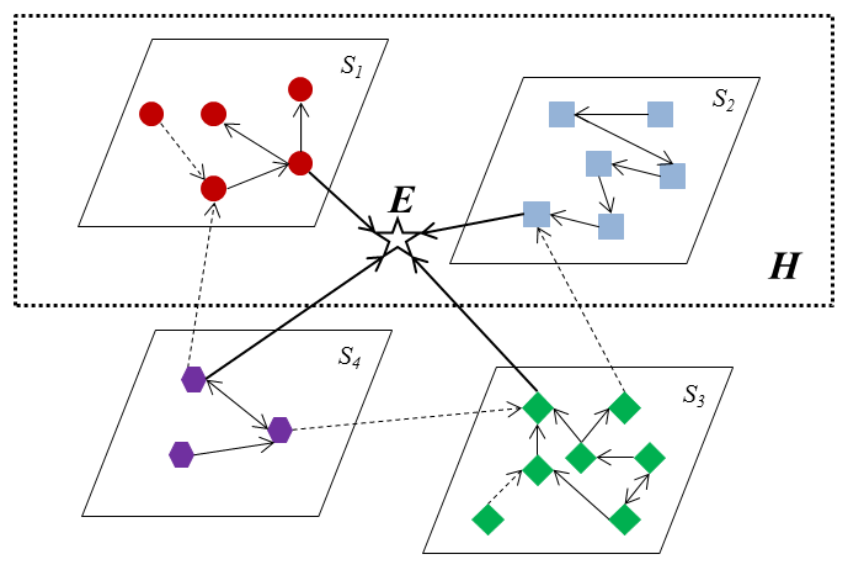

Figure 1: Muir Web representation of a system of systems made of a critical plant, $H$ (dotted-rectangular shape) whose safety is identified in the state of its critical element $E$, and four interdependent systems $S_{i}, i=1, \ldots, 4$, whose elements (represented by circles, squares, rhombs and hexagons, respectively) are connected by direct dependencies (solid lines) and support dependencies (dashed lines). The systems $S_{1}$ and $S_{2}$ are inside the critical plant, whereas the systems $S_{3}$ and $S_{4}$ are outside. The links to the critical element $E$ (star) of the critical plant are the bold lines.

\subsection{Monte Carlo simulation for Seismic Probabilistic Risk Assessment within a system-of-systems framework}

Within the system-of-systems analysis framework here purported, we wish to evaluate the safety of the critical plant $H$ exposed to the risk from earthquakes occurrence, accounting not only for the direct effects of the earthquake on $H$, in particular on the internal interconnected systems $S_{i}, i=1, \ldots, q$, inside $H$, but also for the structural and functional responses of the $N_{c_{i}}, i=q+1, \ldots, N_{S}$, components and their impacts on the systems $S_{i}, i=q+1, \ldots, N_{S}$, and eventually on the critical plant $H$ through the interconnected web of the underlying dependency structure. To do this, we adopt the Muir Web representation of the system of systems and Monte Carlo (MC) simulation for the quantitative SPRA evaluation [25]. The simulation procedure consists of the following operative steps:

1. sample a magnitude value from the double truncated exponential distribution by equation 1;

2. compute the ground motion value at each of the $N_{c_{i}}, i=1, \ldots, N_{S}$, components of the systems $S_{i}, i=1, \ldots, N_{S}$, by equation 2 ;

3. compute the fragility, $f$, for all the components $N_{c_{i}}, i=1, \ldots, N_{S}$, of the systems $S_{i}$, $i=1, \ldots, N_{S}$, by equation $3 ; f$ is a vector of $N$ values corresponding to the $N$ components of the system; 
4. sample a matrix $\left\{u_{j, k}\right\}, j=1, \ldots, N_{T}, k=1, \ldots, N$, where $N_{T}$ is the number of simulations, of uniform random numbers in $[0,1)$;

5. determine the fault state matrix $\left\{g_{j, k}\right\}, j=1, \ldots, N_{T}, k=1, \ldots, N$, by comparing the fragility, $f$, with the matrix $\left\{u_{j, k}\right\}, j=1, \ldots, N_{T}, k=1, \ldots, N$ : if $f_{k}<u_{j, k}, g_{j, k}=1$; otherwise $g_{j, k}=0$ for $j=1, \ldots, N_{T}$ and $k=1, \ldots, N$. When $\left\{g_{j, k}\right\}$ assumes value 1 , the $k$-th component is affected by the earthquake, i.e., it enters a faulty state; otherwise, it survives. Each row of the matrix $g$ represents the states of the $N$ system components;

6. determine the state of the critical plant $H$, considering:

a. the impact of the earthquake on $H$, i.e., taking into account the interconnected systems $S_{i}, i=1, \ldots, q$, inside the plant.

b. the impact of the earthquake both on $H$, i.e., taking into account the interconnected systems $S_{i}, i=1, \ldots, q$, inside the plant, and on the interconnected systems $S_{i}, i=q+1, \ldots, N_{S}$, outside the plant.

The state of $H$ is identified by the analysis of the states of the $N_{\text {in }}$ components of the systems $S_{i}, i=1, \ldots, q$, for the case a., and of the $N$ components of the systems $S_{i}$, $i=1, \ldots, N_{S}$, for the case $\mathrm{b}$., together with the analysis of the dependence of $H$ from the services provided by the systems, as represented in the Muir Web model. The structure of dependence represented in the Muir Web drives the identification of the functional logic relations among the components within each system (intra-system links) and among different systems (inter-system links). Knowledge of these relations allows identifying the state of the critical plant $H$ on the basis of the states of the components of its connected systems and their logic links: trivially, if two components of a system are connected in series (Figure 2, left), they should be both in an operational state to guarantee its functioning; on the contrary, if they are connected in parallel (Figure 2, right), at least one of them should work.
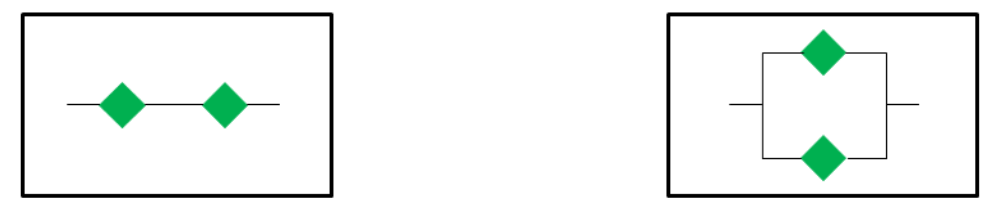

Figure 2: Example of series (left) and parallel (right) configurations between two components. 
The state of $H$ is evaluated through the analysis of the logic connections between the components, as explained above, for each row of the matrix $\left\{g_{j, k}\right\}$, i.e., for all the $k$ states determined at step 5 , where $k=1, \ldots, N_{\text {in }}$ and $k=1, \ldots, N$ for the case a. and b. above, respectively, and for all the simulations $j, j=1, \ldots, N_{T}$. A vector $\left\{h_{j}\right\}, j=$ $1, \ldots, N_{T}$, is then recorded, whose element assumes value 1 when the critical plant $H$ is in an unsafe state and 0 otherwise;

7. estimate the probability of the critical plant $H$ of being unsafe by computing the sample average of the values of the vector $\left\{h_{j}\right\}, j=1, \ldots, N_{T}$.

The procedure above is repeated a large number of times for different values of earthquake magnitude.

Note that the components are considered with binary states: fully operative or completely damaged and also the critical plant can assume only two states: fully operative or totally failed. This approximation is not realistic and leads to pessimistic results: multi-state modeling may be considered for a more realistic description, where different degrees of damage are contemplated.

This framework of analysis should also allow considering the duration of the recovery actions to restore the safe state of the critical plant. This aspect is not here examined, but it is intended to be the objective of future work.

\section{CASE STUDY}

We consider the analysis of the safe state of a nuclear power plant (the critical plant), provided with proper internal emergency devices, in response to an earthquake (the external event). The nuclear power plant is considered in a safe condition if it does not cause health and environmental damages, i.e., if it does not release radioactive material to the environment; to maintain this state it must be provided with electrical and water inputs to absorb the heat that it generates. The boundaries of the analysis extend to the responses of the external interconnected systems that provide inputs necessary to keep or restore the plant in the safe state. In Section 4.1, the description of the specific system studied is given under a number of assumptions aimed at simplifying the problem to the level needed to convey the key aspects of the conceptual system-of-systems framework, while maintaining generality. 
When an earthquake occurs, the critical plant may not receive the input necessary to be kept in, or restored to, a safe state due to the direct impact on its internal emergency devices (safety systems) and to the damages to the external interconnected infrastructures. In general, two quantities can be of interest with regard to the loss of functionality of the various components of the system of systems embedding the critical plant, upon the occurrence of a damaging external event:

- the probability that the critical plant remains in a safe condition given the possible failure configuration of the components;

- the recovery time of the safe state of the critical plant, i.e., the duration of the recovery actions needed to bring the components back to the level of functionality required to restore the safe condition of the plant.

We limit the analysis to the first quantity, leaving the computation of the second one for future work, and in Section 4.2 we provide the results of the evaluation, accompanied by some critical considerations.

\subsection{Description of the physical system and its view as a system of systems}

The system under analysis is composed by a critical plant, i.e., a nuclear power plant, $H$, and five interconnected infrastructure systems, $S_{i}, i=1, \ldots, 5$, that provide services that can serve keeping the safe state of the nuclear power plant. The systems $S_{1}$ and $S_{2}$ are inside the nuclear power plant, whereas the systems $S_{3}, S_{4}$ and $S_{5}$ are outside. The external systems are the power system, $S_{3}$, that provides electrical energy, the water system, $S_{4}$, that provides coolant useful for absorbing the heat generated in the nuclear power plant, and the road network, $S_{5}$, that is important for the transport of material and plant operators. The internal systems, $S_{1}$ and $S_{2}$, are the power and water systems, respectively, that represent the emergency systems of the plant which needs to obviate at the absence of input from the main systems.

In Figure 3, the physical representation of the system is reported referring to a Cartesian plan $(x, y)$ with origin in a river. The nuclear reactor is the element of the nuclear power plant that must be provided with the necessary inputs to assure the safe state of the entire plant. Table 2 reports the fragility parameters $A_{m}, \beta_{r}$ and $\beta_{u}$, adopted in this analysis, for illustration purposes. The values for the pump and the pipe components have been taken from [26] and [27], respectively, whereas the others fragility parameters have been assumed arbitrarily by the authors to perform the study with different values. Given the large scale system under analysis, two types of soil are considered, rock and soft soil. Figure 4 represents the spatial 
localization of the system shown in Figure 3 with reference to the reciprocal position of all the components (Figure 4, left) and to the position of the system, with respect to three earthquake's epicenters, $A, B, C$ (Figure 4, right). The distances on the axes are expressed in kilometers.

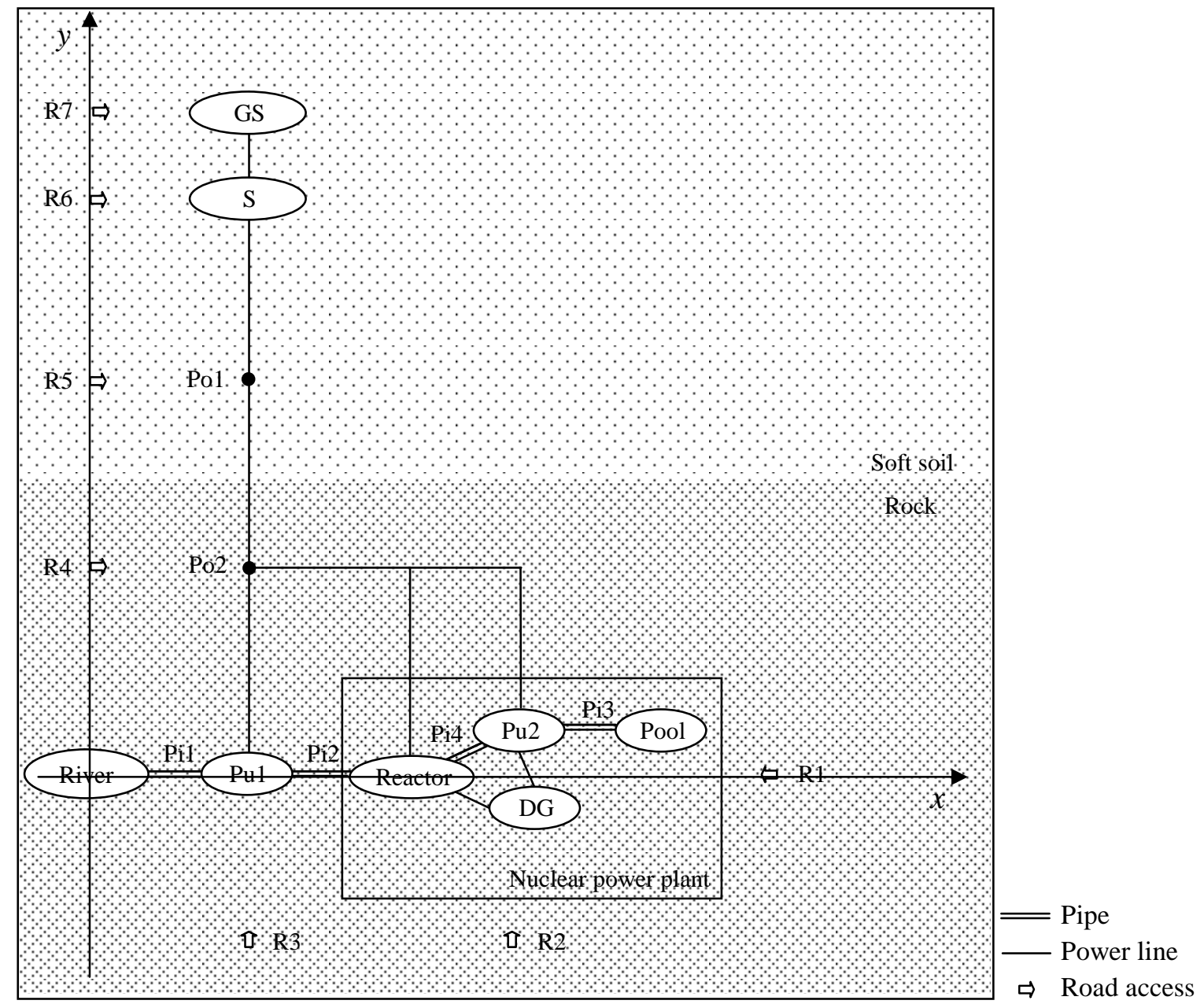

Figure 3: Physical representation of the system. GS: Generation Station, S: Substation, Po: Pole, Pi: Pipe, Pu: Pump, DG: Diesel Generator, R: Road access.

Table 2: Fragility parameters used in the present work.

\begin{tabular}{|l|c|c|c|}
\hline & $A_{m}$ & $\beta_{r}$ & $\beta_{u}$ \\
\hline Generation station & 0.7 & 0.3 & 0.1 \\
\hline Substation & 0.9 & 0.4 & 0.3 \\
\hline Power Pole & 0.8 & 0.2 & 0.2 \\
\hline Diesel Generator & 0.7 & 0.4 & 0.2 \\
\hline Pipe & 1.88 & 0.43 & 0.48 \\
\hline Pump & 0.2 & 0.2 & 0.3 \\
\hline Pool & 0.2 & 0.1 & 0.1 \\
\hline Road & 0.3 & 0.3 & 0.2 \\
\hline
\end{tabular}



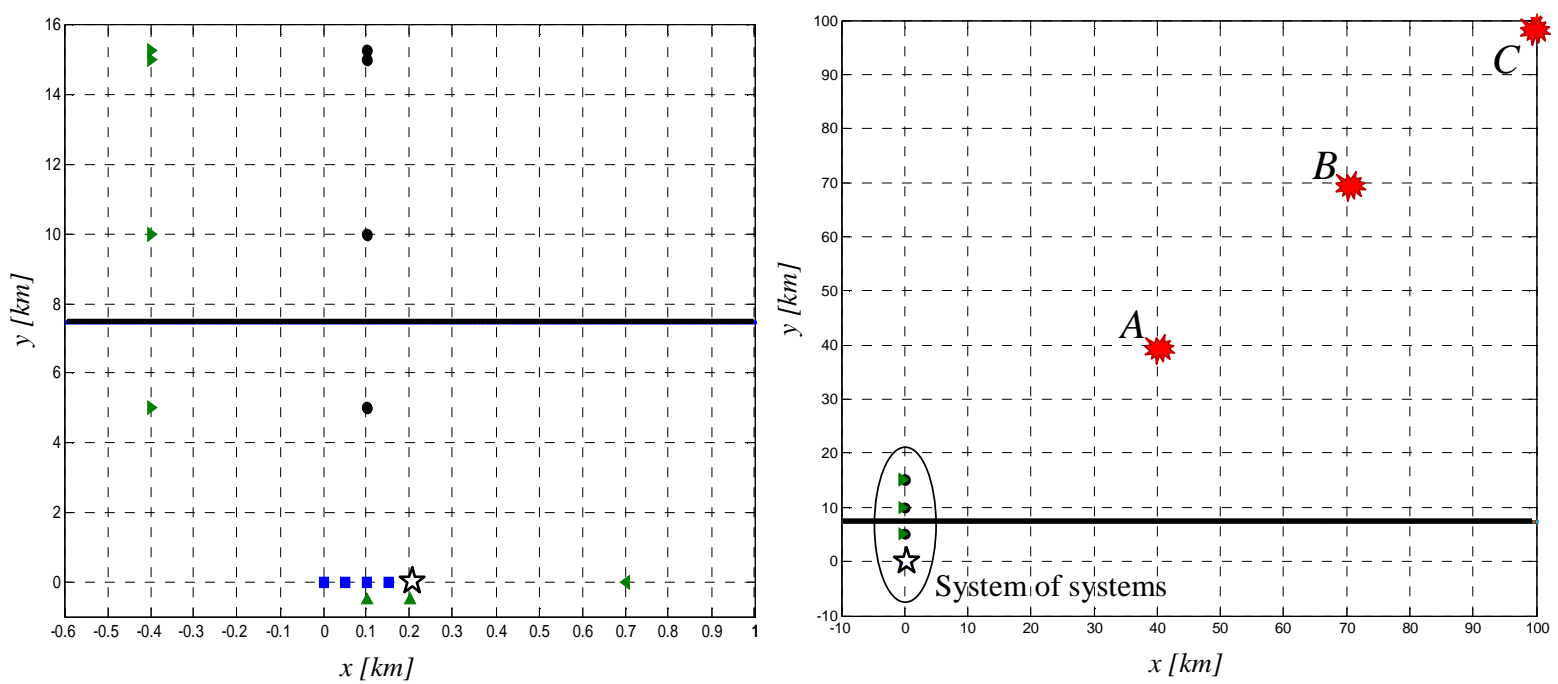

Figure 4: Left: spatial localization of the nuclear reactor (star), which identifies the nuclear power plant, with respect to the components of the electric power system (circle, from top to bottom: Generation Station,

Substation, Pole 1, Pole 2), water system (square, from left to right: River, Pipe 1, Pump 1, Pipe 2) and road transportation (triangle, from top to bottom and from left to right: $R 7, R 6, R 5, R 4, R 3, R 2, R 1$ ). Right: spatial localization of the system of systems with respect to three earthquake's epicenters $A(40,40), B(70,70), C(100$, 100). The horizontal bold line in both Figures represents the division between soft soil (above the line) and rock (below the line).

In Figure 5, the system-of-systems representation is given by the Muir Web showing the physical components of the infrastructure systems and factors which they depend on. In this representation the connections among the elements are depicted without expliciting the types of dependencies introduced in Section 3.2 which are illustrated in Figure 6.

The external water distribution system (Figure 5, left) is formed by a source of water (e.g., a river), a pump and pipes that carry the water. The failure probability of these elements when subjected to earthquake shocks depends on the type of soil, the design and materials of construction, and the maintenance. Operators are in charge of the maintenance of the structural elements and mechanical components.

The external power distribution system (Figure 5, center) is composed by the following elements: a generation station that produces the electrical energy, a substation that transforms the voltage from high to low, power lines and poles to support them, the type of soil on which the infrastructures rest, and the operators that run the generation station and provide the maintenance for all its elements and components. 
The components of the emergency water and power distribution systems inside the plant are shown in Figure 5 on the right. The first system is composed by the same elements of the correspondent external system except for the source of water that is an artificial reservoir (e.g. a tank or pool), whereas the power system includes only the emergency diesel generators.

The elements considered for the transportation system are the roads (Figure 5, top). The state of this system is important for access of the materials and operators needed to keep or restore the functionality of the components required for the safe state of the critical plant.

Actually, in view of the methodological character of this work, for the sake of simplicity, the influence of the design construction and materials, the supply of fuel and materials for plant operation, and the maintenance tasks are not included in the analysis. Failure of the power lines, being aerial elements and therefore being not directly affected by an earthquake, is also not considered. Finally, the assumption is made that the river is not perturbed by the earthquake, so that it is a source of water always available.

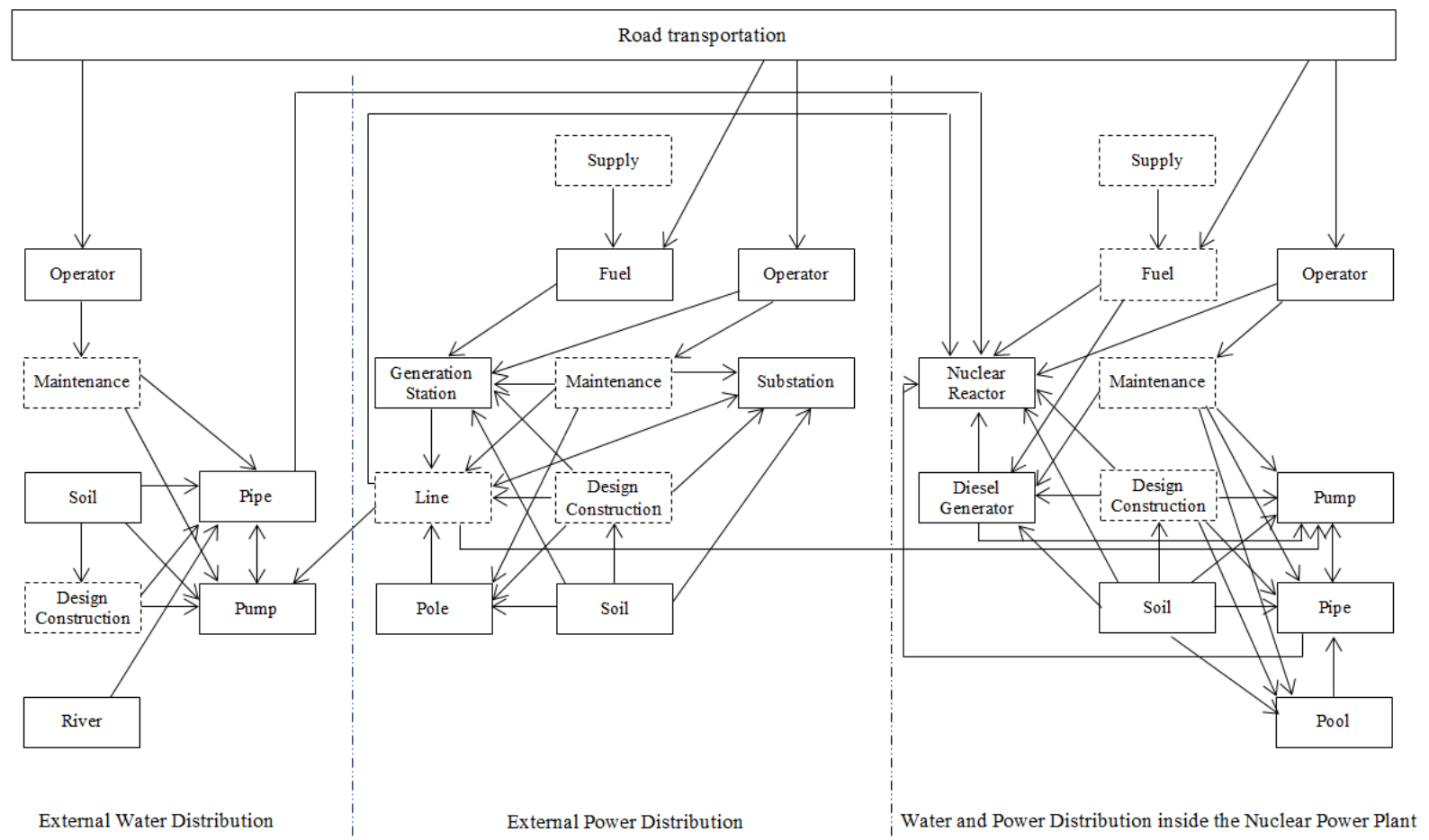

Figure 5: Muir Web of the system of systems: the elements in the dashed box are not considered in the present study.

In Figure 5, the inter-system dependencies are modeled as links connecting components of the five systems, $S_{i}, i=1, \ldots, 5$; these connections are of the same nature as those linking components of the individual systems (intra-systems dependencies). An example of these 
connections concerns the water system that depends on the power system as the pump needs electrical energy to work. This component receives the electrical energy from the external power distribution network; on the contrary, it is assumed that the pump inside the nuclear power plant can obtain energy from both the external and internal power systems.

The road transport network allows access to the components of the power and water systems for transporting material (e.g., fuel) and/or operators for operation and/or maintenance.

A representation of the Muir Web illustrating the different types of dependencies introduced in Section 3.2 is shown in Figure 6. The nodes are the components (e.g., generation station, pole, pump...) and the links are the dependencies among them. Note that, differently from Figure 5, the pole Po2 of the external power system is directly connected to the pumps of the external and internal water systems and to the nuclear reactor because the power lines are not considered in this work and the closest element to carry the power to the pumps and to the nuclear reactor is that pole. The transport system, $S_{5}$, is composed by seven road access points to the components of the power and water systems. One access is provided for the components outside the nuclear power plant, whereas two accesses are provided for the elements inside. In particular, the components of the external power system are considered to have a different road access because they are far from each other (the minimum distance is $300 \mathrm{~m}$ between the generation station and the substation, Figure 4 left), the components of the external water system have the same road access, R3, because they are located close to each other (the total distance from the river to the nuclear power plant is $200 \mathrm{~m}$, Figure 4 left) and the components of the power and water systems inside the nuclear power plant have the same two road accesses, R1 and R2, since they are contained in the same building. Note that, in the present study, the road plays the role of "reserve component", since we assume that elements that fail can be immediately repaired/replaced if the access to it through the road system does not fail (recovery times are not considered).

Analyzing the dependency links, it can be noticed that:

- "Direct dependencies" (solid lines) exist for the components of systems $S_{2}, S_{3}, S_{4}$ and between the components Po2 - Pu1, Po2 - Pu2, DG - Pu2 and R7 - GS. These links describe the fact that if a component fails, the connected component fails too because it cannot fulfill anymore its function. For example, in the system $S_{4}$, if the pump Pu1 fails, it cannot pump the water and the pipe Pi2 cannot carry it. 
- "Support dependencies" (dashed lines) exist for the road accesses $R 1, R 2, R 3, R 4, R 5$, $R 6$ and their corresponding components, since they are useful for transporting operators when maintenance or repair of a component is needed. Therefore, they are a support for those components.

- "Connections to the nuclear reactor" (bold lines) link the components of the systems $S_{1} S_{2}, S_{3}, S_{4}$ to the nuclear reactor.

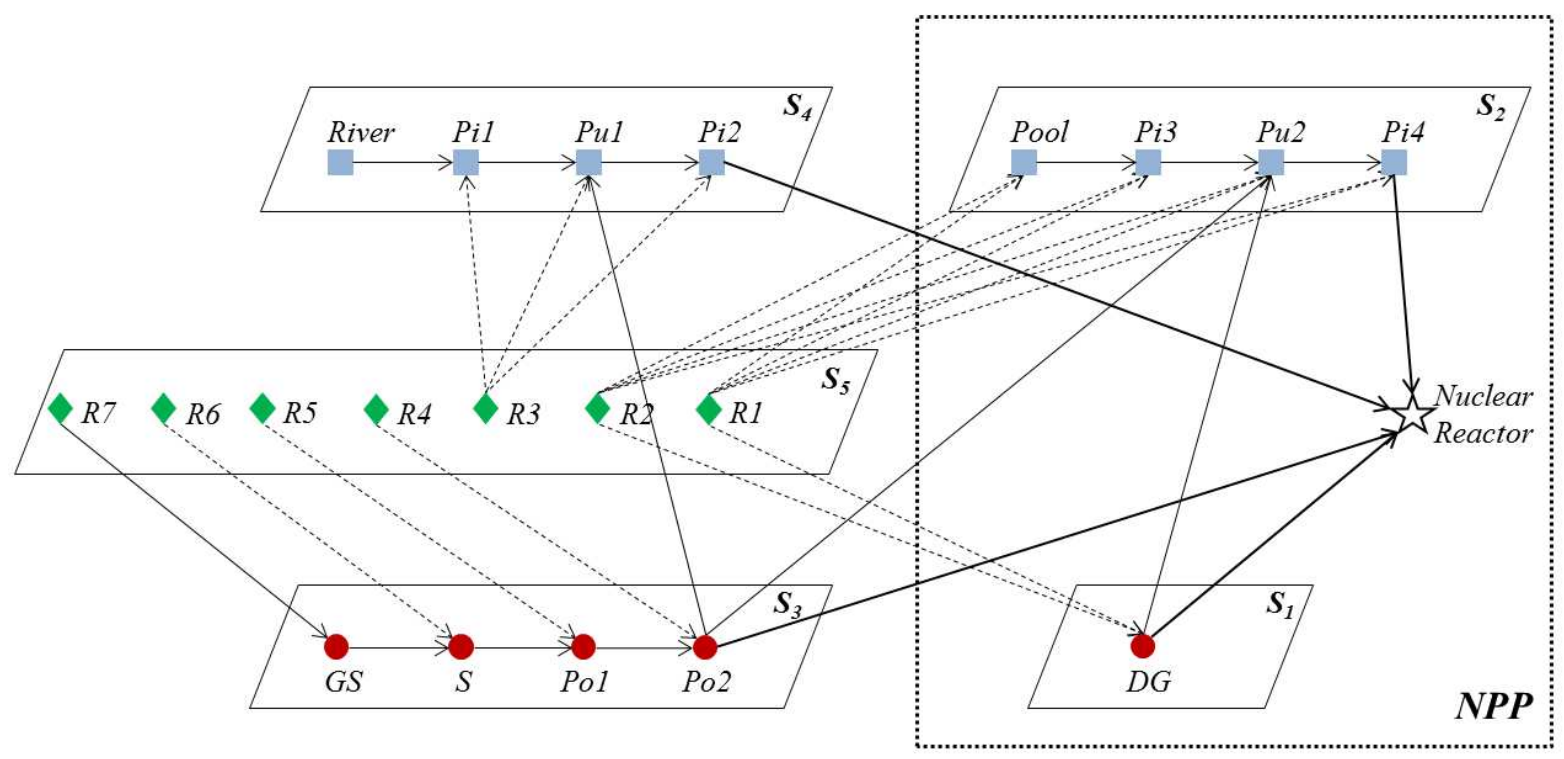

Figure 6: Representation of the physical components of the Muir Web of Figure 5, highlighting the different types of dependencies. The interconnected systems $S_{i}, i=1, \ldots, 5$, can provide services relevant to the safe state of the nuclear power plant (NPP). The links represent the direct dependencies (solid lines), the support dependencies (dashed lines) and the dependencies of the nuclear reactor (star) on its interconnected systems (bold lines). GS: Generation Station, S: Substation, Po: Pole, Pi: Pipe, Pu: Pump, DG: Diesel Generator, R: Road access, $S_{1}$ : internal power system, $S_{2}$ : internal water system, $S_{3}$ : external power system, $S_{4}$ : external water system, $S_{5}:$ Road transportation.

From the Muir Web and the knowledge of the functionality of the components of the system of systems, it is possible to identify the logic relations among them. For example, in the system $S_{3}$, there is a flow of energy that starts from the generation station where it is produced, passes into the substation where it is converted into a low voltage and reaches the final destinations, i.e., the nuclear reactor and the water systems $S_{2}$ and $S_{4}$, through the poles 1 and 2. All these components are connected in series (Figure 7) because if one of them fails, the entire system $S_{3}$ fails, i.e., it cannot fulfill anymore its function of providing energy. With the same reasoning, it can be evidenced that the components within the systems $S_{2}$ and $S_{4}$, are 
connected in series too. Instead, the components of the system $S_{5}$ are independent and the system $S_{1}$ contains only one element.

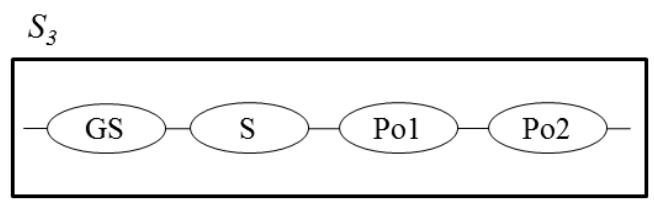

Figure 7: Logic connections between the components of the external power system, $S_{3}$. GS: Generation Station,

\section{S: Substation, Po: Pole}

Given the assumption of instantaneous recovery of a component if the road access to it is available, we can consider the road access like a "reserve component" in parallel with the corresponding element to which it provide access. In Figure 8, the logic connections between the systems $S_{3}-S_{5}$ are provided. Note that the road $R 7$ plays a double role in the external energy subsystem: it provides the generation station with access for 1) maintenance and repair (as the other road accesses $R 1, R 2, R 3, R 4, R 5, R 6$ ) and 2) operators and materials necessary to its operation. Therefore, the damage to this road access can cause the stop of the generation station and, as a consequence, the failure of the external power system $S_{3}$. For this reason, the road $R 7$ is in series with the system $S_{3}$ and in parallel with the generation station GS.

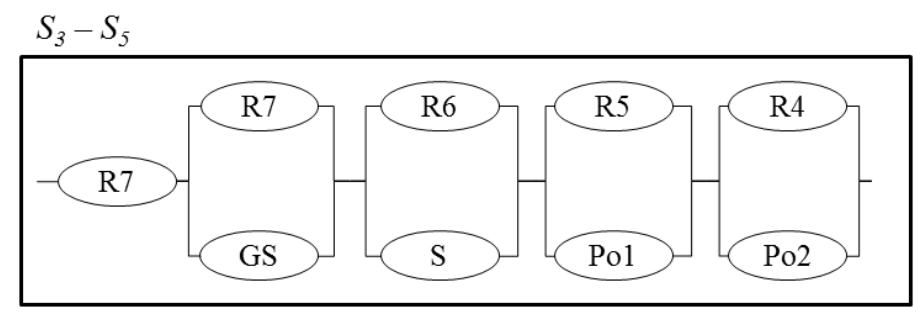

Figure 8: Logic connections between the components of the external power system, $S_{3}$, and those of the road transportation, $S_{5}$. GS: Generation Station, S: Substation, Po: Pole, R: Road access.

Figure 9 reports the logic relations between the systems $S_{4}-S_{5}$ (on the left), $S_{2}-S_{5}$ (in the middle) and $S_{1}-S_{5}$ (on the right).
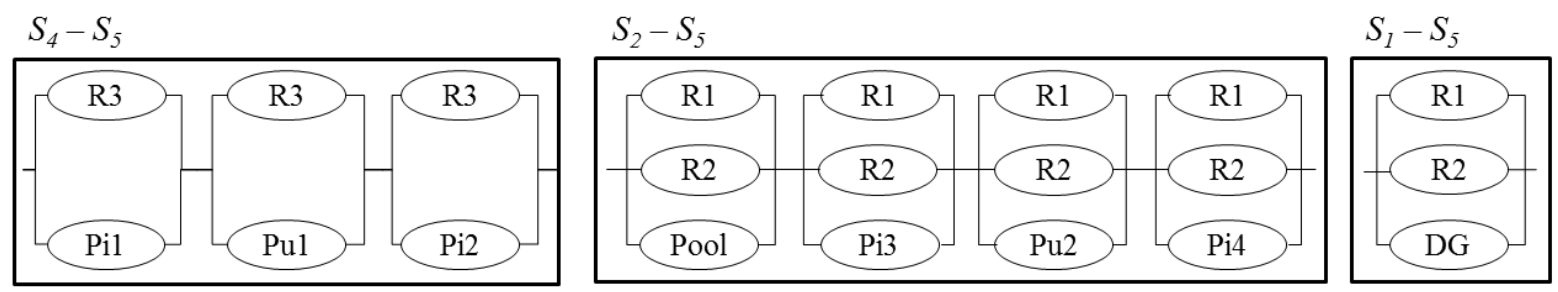

Figure 9: Logic connections between the components of the external water system, $S_{4}$, internal water system, $S_{2}$, internal power system, $S_{1}$, and those of the road transportation, $S_{5}$. GS: Generation Station, S: Substation, Po: Pole, Pi: Pipe, Pu: Pump, DG: Diesel Generator, R: Road access. 
The power and water systems are connected in series as the pump in the water system needs energy to work. In particular, the external power system, $S_{3}$, is in series with the internal and external water systems, $S_{2}$ and $S_{4}$, respectively, and the internal power system, $S_{1}$, is in series with the internal water system, $S_{2}$, as shown in Figure 10.
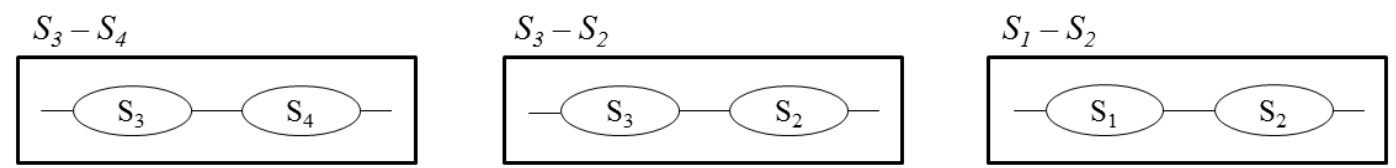

Figure 10: Logic connections between the power and water systems. $S_{1}$ : internal power system, $S_{2}$ : internal water system, $S_{3}$ : external power system, $S_{4}$ : external water system.

Figure 11 integrates the logic relations among the systems $S_{i}, i=1, \ldots, 5$, to maintain the safe state of the nuclear power plant.

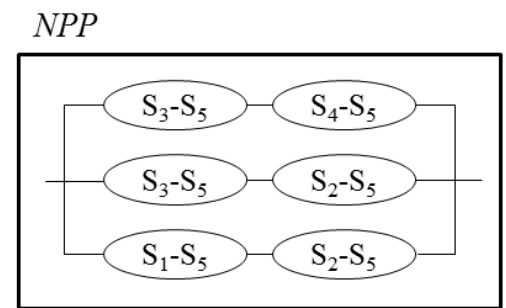

Figure 11: Logic connections between the interconnected systems $S_{i}, i=1, \ldots, 5$, to the nuclear power plant (NPP). $S_{1}$ : internal power system, $S_{2}$ : internal water system, $S_{3}:$ external power system, $S_{4}:$ external water system, $S_{5}$ : road transportation.

\subsection{Results and limitations}

Figure 12 shows the results of the Monte Carlo simulation for Seismic Probabilistic Risk Assessment carried out with the operative procedure illustrated in Section 3.3 applied to the case study described above, regarding the system of systems represented by the Muir Web of Section 3.2. For each magnitude level sampled from a truncated exponential probability distribution (1) with lower threshold $m_{\min }=5$ and upper bound $m_{\max }=7$, the estimate of the probability of the nuclear power plant (NPP) to reach an unsafe condition, is computed. The number of magnitude values sampled is 1000 and the number of simulations $\left(N_{T}\right)$ of the components configuration for each value of magnitude is 5000 . 


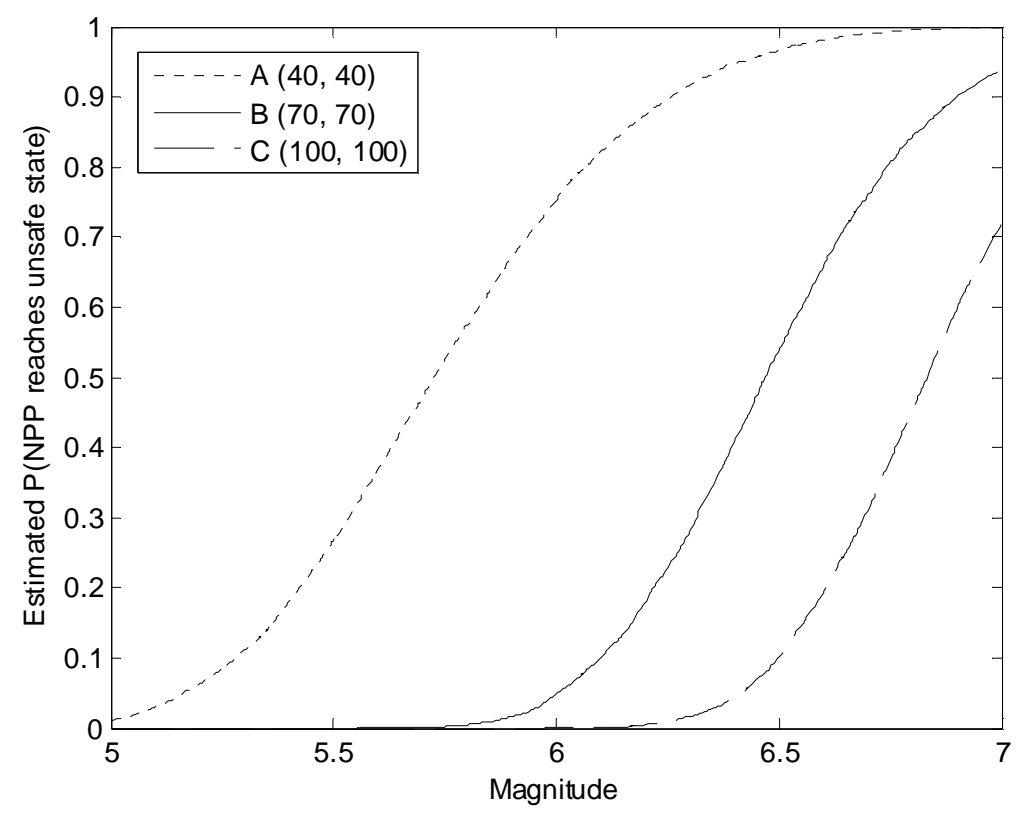

Figure 12: Estimate of the probability that the nuclear power plant reaches an unsafe state after an earthquake of a given magnitude on the basis of different source-to-site distances. With reference to the map of Figure 4, the coordinates of the earthquake's epicenters considered are $A(40,40), B(70,70), C(100,100)$, expressed in kilometers.

The analysis is carried out for the three earthquake's epicenters, $A, B, C$, shown in Figure 4. As expected, the higher the distance, the lower is the probability that the safety of the nuclear power plant cannot be assured.

Figure 13 shows the comparison between the probabilities that the nuclear power plant turns into an unsafe condition after the occurrence of an earthquake, considering it both as an isolated plant provided with its emergency devices (case of independence) and as embedded in the system of systems of the supporting infrastructures (case of dependence). 

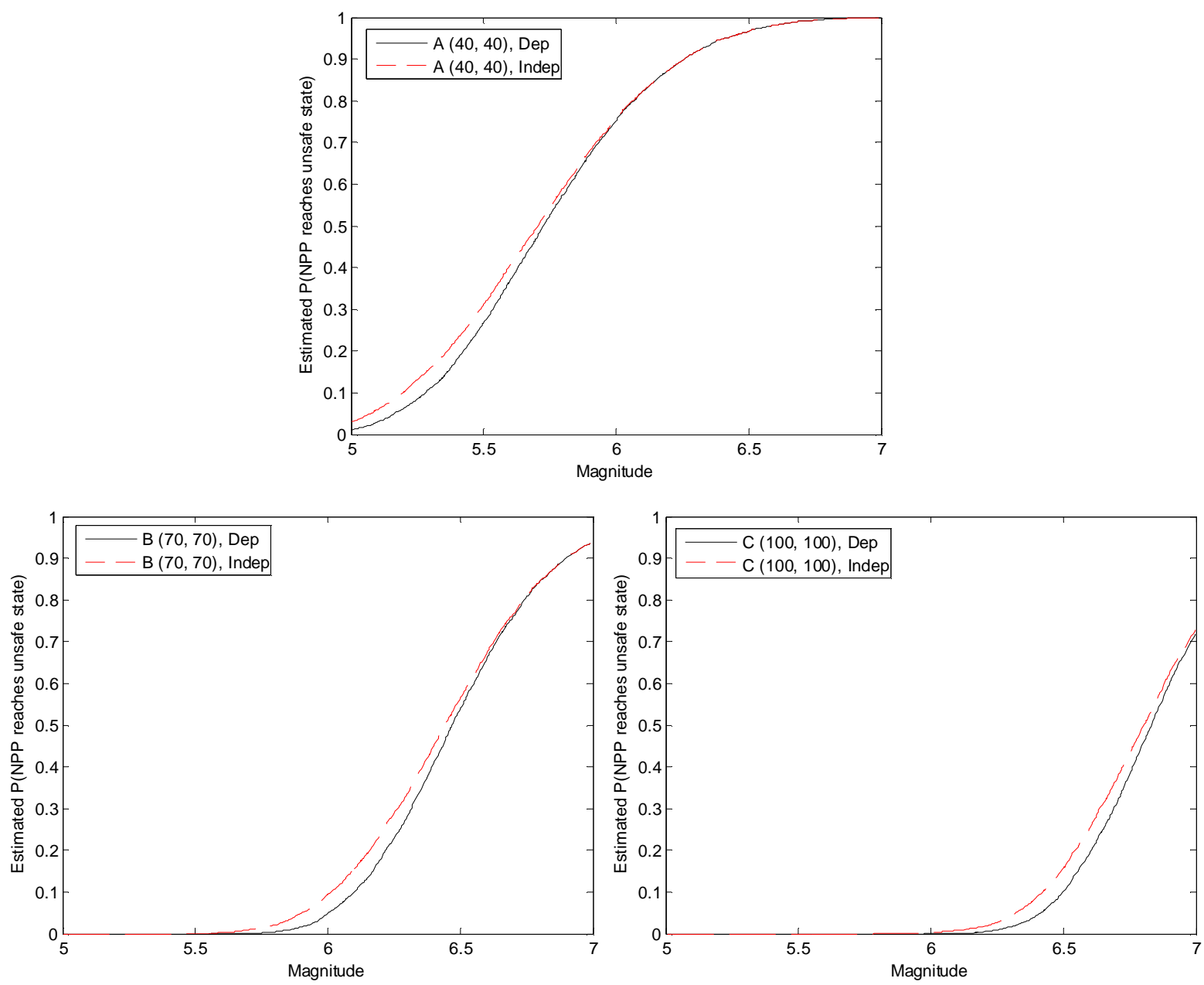

Figure 13: Comparison between the results of the MC simulation in the case of dependence (solid line) of the nuclear power plant on the connected infrastructure systems, and in the case of independence (dashed line). The analysis is carried out for three earthquake's epicenters: $A(40,40)$ on the top, $B(70,70)$ on the left and $C(100$, 100) on the right.

It can be seen that, with the given assumptions and data:

- the probabilities to reach an unsafe state computed in case of dependence are slightly lower than those computed in case of independence. This result shows that in principle the infrastructures in the surrounding of the critical plant can contribute to its resilience, offering additional possibilities for maintaining (or restoring) a safe condition;

- the larger difference between the probabilities computed in the case of dependence and independence results for low magnitude values when the source-to-site distance is small, e.g., for magnitudes lower than 5.8 in the case $A(40,40)$ (Figure 13, top), and for high magnitudes when the source-to-site distance increases, e.g., for magnitudes between 5.8 and 6.5 in the case $\mathrm{B}(70,70)$, and for magnitudes higher than 6.2 in the 
case $\mathrm{C}(100,100)$ (Figure 13 left and right, respectively). This is expected and can be explained as follows. In case of small source-to-site distance, the higher the magnitude the higher are the impacts on all the systems, so it is probable that also the interdependent systems are damaged and they cannot be used as an additional support to maintain (or restore) the nuclear power plant in a safe state; when, instead, the magnitude is small not all the components are affected by the earthquake and the interdependent systems could be useful as an additional support for the safety of the critical plant. In the case of high source-to-site distance, the larger difference between the probabilities computed in the case of dependence and independence is for high magnitudes because the lower values do not have impacts on the system components.

Figure 14, on the right, shows the comparison between the probabilities that the nuclear power plant turns into an unsafe state after the occurrence of an earthquake whose epicenter is in $\mathrm{B}(70,70)$ considering the case of dependence (solid line) presented in Figure 13 (left) and considering each individual infrastructure system as isolated (dashed line), as depicted in the Muir Web of Figure 14, on the left, where all the inter-system links have been removed. This analysis allows highlighting to what extent interdependencies among the infrastructure systems affect the safety of the plant inserting "extra" vulnerabilities to the system of systems.
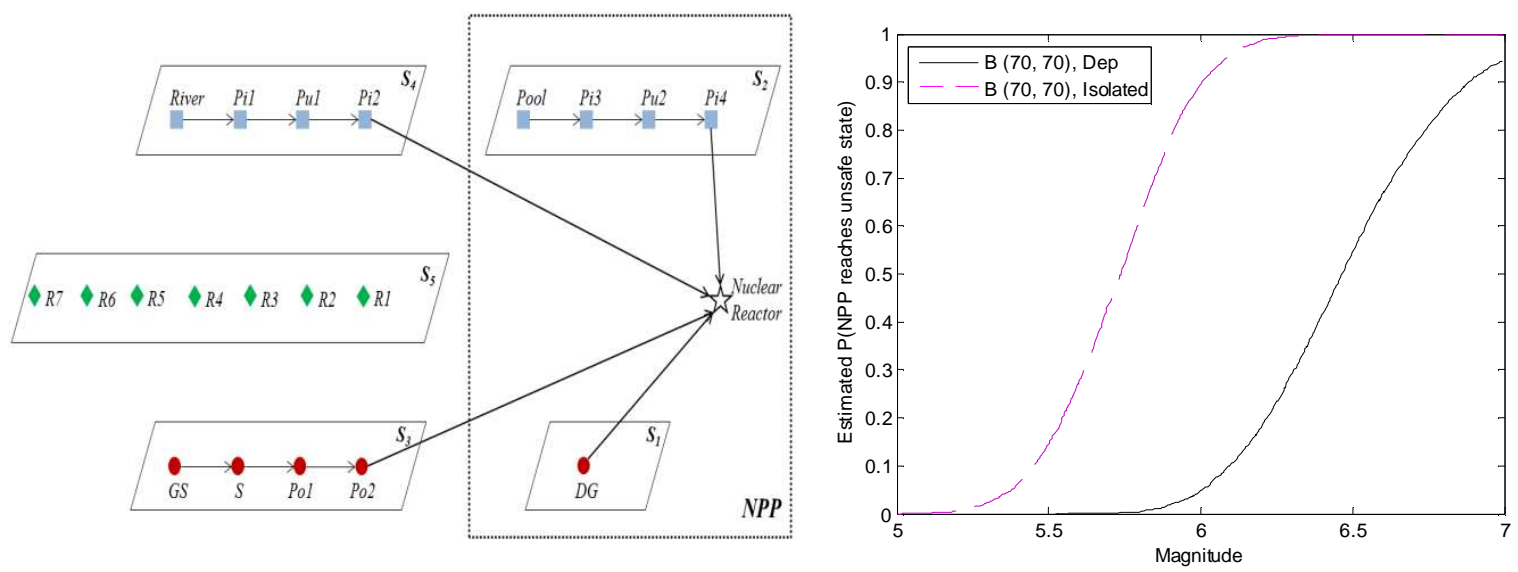

Figure 14: Left: Muir Web of the system of systems of Figure 6 without the inter-system links. Solid lines: direct dependencies, bold lines: connection to the nuclear reactor. GS: Generation Station, S: Substation, Po: Pole, Pi: Pipe, Pu: Pump, DG: Diesel Generator, R: Road access, $S_{1}$ : internal power system, $S_{2}:$ internal water system, $S_{3}$ : external power system, $S_{4}$ : external water system, $S_{5}$ : Road transportation. Right: Comparison between the results of the MC simulation in the case of dependence (solid line) of the nuclear power plant on the connected infrastructure systems and in the case of isolated power, water and road transportation infrastructure systems (dashed line) as shown in the scheme on the left. The analysis is carried out for the earthquake's epicenter B(70, 
The result shows an increase in the probability of unsafe state of the nuclear power plant: this is due to the assumption of instantaneous recovery of the components (Section 4.1) that implies that if a road access is available, the corresponding component is immediately considered operational. Therefore, under this limiting assumption, the connections between the road system and the other systems increase the safety of the nuclear power plant. On the contrary in the realistic situation, this would not be the case. To show this, we have performed another simulation, considering the road accesses as a part of the systems to which they provide access as shown in Figure 15, left. The results obtained are reported in Figure 15, right. The solid line represents the case of dependence as in Figure 13 (left) and 14 (right) and the dashed line the case of isolated water and power systems, considering the road accesses as part of these systems, as explained above. It can be seen that in the first case the probability values are higher than in the second one, the reduction of safety of the nuclear power plant being due to the interdependences between the water and power systems.
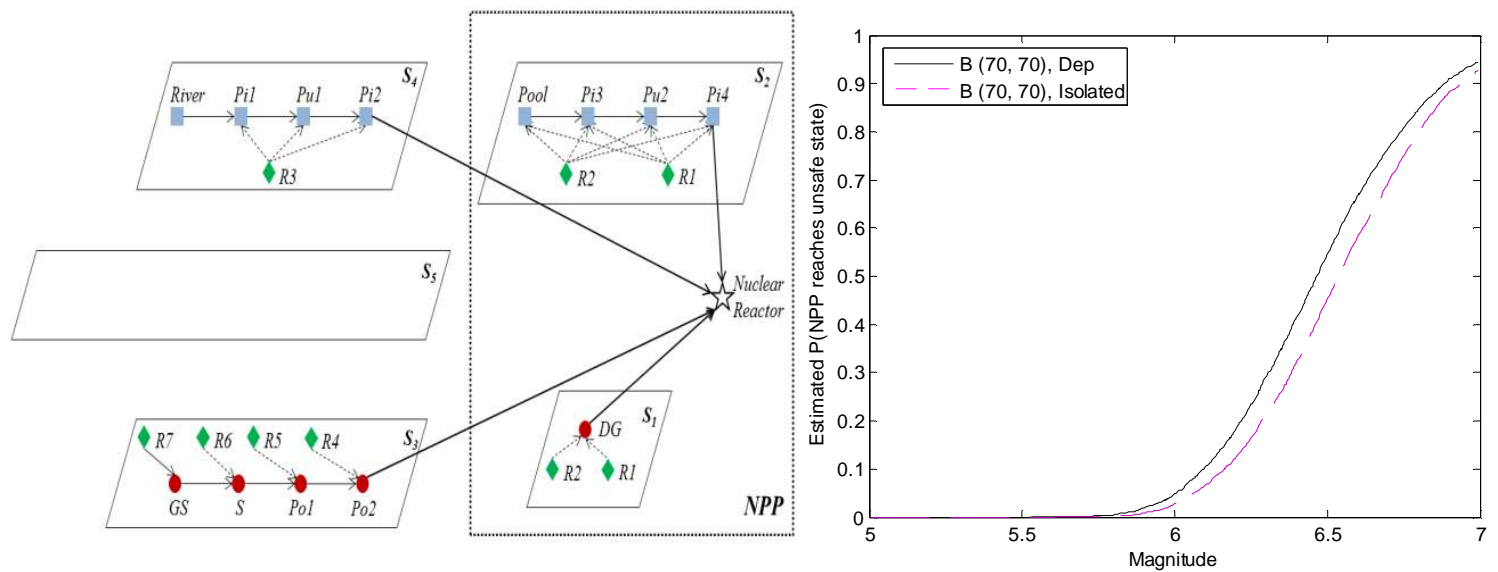

Figure 15: Left: Muir Web of the system of systems of Figure 6 including the road accesses in the corresponding systems to which they provide the access and removing the dependencies between the power and water systems.

Solid lines: direct dependencies, dashed lines: support dependencies, bold lines: connection to the nuclear reactor. GS: Generation Station, S: Substation, Po: Pole, Pi: Pipe, Pu: Pump, DG: Diesel Generator, R: Road access, $S_{1}$ : internal power system, $S_{2}$ : internal water system, $S_{3}:$ external power system, $S_{4}$ : external water system, $S_{5}$ : Road transportation system. Right: Comparison between the results of the MC simulation in the case of dependence (solid line) of the nuclear power plant on the connected infrastructure systems and in the case of isolated power and water systems (dashed line) as shown in the scheme on the left. The analysis is carried out for the earthquake's epicenter $B(70,70)$.

Some limitations of the case study are pointed out in the following. For example, one concerns the assumption of immediate recovery of an element when it fails. Obviously, in practice, it takes time to bring back a component. In this sense, a time recovery distribution 
should be considered to perform a more realistic analysis. Similarly, in specific cases the duration of emergency service supply should be included in the analysis to provide a proper time-dependent picture of the conditions of the critical plant. Also, some potentially influent factors identified in the Muir Web representation have been neglected in order to simplify the quantitative analysis, like the design construction and materials, the maintenance task, etc. Furthermore, as mentioned earlier, a multi-state model should be considered to describe partial failures at the components levels and partial safety at the critical plant level. Finally, as in all risk analyses, uncertainties are present and need to be taken into account. In the specific case study, uncertainty is present in the inputs to the Probabilistic Seismic Hazard Analysis that are based on geological, seismological and geophysical data subjected to expert interpretations, but also in the parameters of the component fragility models. These and other uncertainties may have a considerable role in the result, and the decisions associated to it. In order to develop the case study into a more realistic one, it is necessary to relax some of the assumptions introduced but this will lead to increased analysis and computational costs due to 1) the collection of data needed to evaluate additional factors neglected in the present work and 2) the calculation for evaluating the quantities of interest from a multi-state model with associated uncertainty.

\section{CONCLUSIONS}

We have presented a system-of-systems framework of analysis of the risk of a critical plant from external events, to account for the influence of the interdependent infrastructures in which the plant is embedded.

For illustrating the conceptual framework of the analysis, we have made reference to an earthquake as the external event, a nuclear power plant as the critical plant and the power and water distribution, and transportation networks as the interdependent infrastructure systems. We admittedly simplified many technical details of the systems considered and made opportunistic assumptions for the purpose of preserving the focus on the conceptual, methodological framework of analysis.

We provided a numerical example by resorting to the Muir Web as system analysis tool to build the system-of-systems model and Monte Carlo simulation for the quantitative evaluation of the model.

In particular, the following analyses have been carried out: 
a. a comparison between the probabilities that the nuclear power plant reaches an unsafe state after an earthquake of a given magnitude, depending on different site-to-source distances: as expected, the higher the distance, the lower is the probability to get to an unsafe state;

b. a comparison of the previous probabilities (a.), obtained in the case of dependence of the nuclear power plant on the interconnected infrastructure systems, with those obtained in the case of independence, i.e., considering the nuclear power plant as an isolated system provided only by its internal emergency devices: the results show that the probability to reach an unsafe state is higher in this latter case and, in particular, the "resilience" contribution of the interdependent systems to the safety of the nuclear power plant is significant for low magnitudes when the source-to-site distance is small, and for high magnitudes when the source-to-site distance is big;

c. a comparison of the previous probability (a.) for one earthquake epicenter, obtained in the case of dependence of the nuclear power plant on the interconnected infrastructure systems, with that obtained in the case of isolated infrastructure systems, i.e., removing all the inter-system links and considering all the infrastructure systems as isolated: the results show that the probability to reach an unsafe state is higher in this latter case, due to the particular "redundancy" role of the road accesses under the assumption of immediate recovery of the components;

d. the same comparison as in c., but considering, for the isolated case, the dependence between the road accesses and the corresponding components and maintaining the independence among the other systems: the results show that in this case the probability to reach an unsafe state is lower; this means that the inter-system links among the power and water systems increase the probability of failure of the system of systems and, thus, of the nuclear power plant being in an unsafe state.

The results of the analyses, albeit performed on a simplified case study and under limiting assumptions, highlight that the interdependent infrastructure systems may play a role for the safety of a critical plant, and it thus seems advisable to include them in the analysis framework. In fact, they can provide additional support to the safety of the critical plant providing inputs necessary for its safe operation (results of case b. above), but their contribution can be reduced by their interconnections as shown in the case d. above. This is relevant as it can lead to considerations with respect to the decision making related to safety- 
critical issues. One may even imagine considering the optimization of some controllable characteristics of the system of systems with the objective of increasing the safety of the critical plant. This could be done by a thorough analysis to identify the most important elements in the system of systems and a cost/benefit analysis to rationally direct the investments of efforts and resources for improving their structural/functional responses, within a comprehensive system-of-systems approach.

Note that although the driving case study for the illustration of the framework has considered a nuclear power plant as the critical plant, others can be analyzed with their specificities, e.g., chemical process and oil \& gas plants or refineries which can release toxic material, develop fires and explosions. For example, loss of offsite power occurred during operation of a vinyl chloride monomer plant at Sodegaura, Chiba (Japan) after a strong earthquake in 1987. In that occasion, the emergency power generator started, as expected, but then it was stopped. As a consequence of the total power failure, the alkali circulation pump of the absorber stopped and the hydrochloric acid gas was released leading to environmental pollution [28].

Future research work will be devoted to apply the framework of analysis presented to diverse systems of systems, with different specificities, and to improve it, for example, by introducing the time needed to recover the safe state of the critical plant and considering a multi-state model for the components of the system of systems. The new case studies will also allow evaluating further the Muir Web representation model and what it is capable to do that other techniques cannot do.

\section{REFERENCES}

[1] International Atomic Energy Agency. Development and Application of Level 1 Probabilistic Safety Assessment for Nuclear Power Plants. Vienna (AT): IAEA Safety Standards; 2010. Specific Safety Guide No. SSG-3. Chapter 8, Specifics of level 1 PSA for external hazards; p. 91-114.

[2] International Atomic Energy Agency. The great east Japan earthquake expert mission IAEA international fact finding expert mission of the Fukushima Dai-ichi NPP accident following the great east Japan earthquake and Tsunami. Mission Report 24 May -2 Jun 2011. 162 p. 
[3] Adachi T, Ellingwood BR. Serviceability of earthquake-damaged water systems: Effects of electrical power availability and power backup systems on system vulnerability. Reliability Engineering \& System Safety. 2008; 93(1):78-88.

[4] Aven T. On Some Recent Definitions and Analysis Frameworks for Risk, Vulnerability, and Resilience. Risk Analysis. 2011; 31(4):515-522.

[5] Eusgeld I, Nan C, Dietz S. "System-of-systems" approach for interdependent critical infrastructures. Reliability Engineering \& System Safety. 2011; 96(6):679-686.

[6] Haimes YY. On the Complex Definition of Risk: A Systems-Based Approach. Risk Analysis. 2009; 29(12):1647-1654.

[7] Johansson J, Hassel H. An approach for modelling interdependent infrastructures in the context of vulnerability analysis. Reliability Engineering \& System Safety. 2010; 95(12):1335-1344.

[8] Kröger W, Zio E. Vulnerable systems. London: Springer; 2011. 63 p.

[9] Wang S, Hong L, Chen X. Vulnerability analysis of interdependent infrastructure systems: a methodological framework. Physica A: Statistical Mechanics and its Applications. Forthcoming 2012.

[10] Sanderson EW. Mannahatta: A natural history of New York Ciy. New York: Abrams; 2009. $352 \mathrm{p}$.

[11] Kalos MH, Whitlock PA. Monte Carlo methods. Vol. 1, Basics. New York: Wiley; 1986. $186 \mathrm{p}$.

[12] Marseguerra M, Zio E. Basics of the Monte Carlo Method with Application to System Reliability. Hagen(DE): LiLoLe - Verlag GmbH; 2002. 141 p.

[13] Zio E. Computational methods for reliability and risk analysis. Series on Quality, Reliability and Engineering Statistics, Vol 14. Singapore: World Scientific Publishing Co. Pte. Ltd.; 2009. Chapter 2, Monte Carlo simulations for reliability and availability analysis; p. 59-69.

[14] LaRocca S, Guikema SD, Cole J, Sanderson E. Broadening the discourse on infrastructure interdependence by modeling the "Ecology" of infrastructure systems. In: Application of Statistics and Probability in Civil Engineering. Faber, Kohler \& Nishijima (eds). London: Taylor \& Francis Group; 2011. p. 1905-1912.

[15] Seismic Probabilistic Risk Assessment Implementation Guide, EPRI, Palo Alto, CA: 2003. TR-1002989. 
[16] Recommendations for Probabilistic Seismic Hazard Analysis: Guidance on Uncertainty and Use of Expert. Main Report, Vol. 1. 1997, NUREG/CR-6372 UCRL-ID- 122160. Supported by U.S. Nuclear Regulatory Commission (NRC), the U.S. Department of Energy (DOE); and the Electric Power Research Institute (EPRI).

[17] Sen TK. Fundamentals of seismic loading and structures. Singapore: John Wiley \& Sons, Ltd; 2009. Chapter 7, Probabilistic Seismic Hazard Analysis; p. 181-218.

[18] Gutenberg B, Richter CF. Frequency of earthquakes magnitude in California, Bulletin of the Seismological Society of America. 1944; 34:185-188.

[19] Kanamori H. The energy release in great earthquakes. Journal of Geophysical Research. 1977; 82(20): 2981-2987.

[20] Kanamori H, 1983. Magnitude scale and quantification of earthquakes. In: SJ. Duda and K. Aki Editors. Quantification of Earthquakes. Tectonophysics, 93: 185-199.

[21] Kramer SL, Geotechnical Earthquake Engineering, Prentice Hall, New Jersey. 1996.

[22] Weatherill GA, Burton PW. The application of multiple random earthquake simulations to probabilistic seismic hazard assessment in the Aegean region. Firs European Conference on Earthquake Engineering and Seismology. Geneva, Switzerland. 2006.

[23] Ambraseys NN, Douglas J, SARMA SK, Smit PM. Equations for the estimation of strong ground motions from shallow crustal earthquakes using data from Europe and the Middle East: horizontal peak ground acceleration and spectral acceleration. Bulletin of Earthquake Engineering. 2005; 3:1-53.

[24] Muir J. Notebook, July 27, 1869. In: The John Muir Papers, 1858-1957. Limbaugh and Lewis Editors. Chadwyck-Healey, Alexandria, VA, 1985.

[25] Huang YN, Whittaker AS, Luco N. A probabilistic seismic risk assessment procedure for nuclear power plants: (I) Methodology, Nuclear Engineering and Design. 2011; 241: 3996- 4003.

[26] Varpasuo P. Seismic fragility analysis of selected heavy components in LNNP unit1 reactor building. Transactions of the 17th International Conference on Structural Mechanics in Reactor Technology (SMiRT). Prague, Czech Republic, August 17-22, 2003.

[27] Basu PC. Seismic fragility of nuclear installations. Atomic Energy Regulatory Board. Mumbay, India. 2008. Presentation: http://civil.iisc.ernet.in/basu.pdf 
[28] Itagaki H, Tamura M. Case details: Partial leakage of hydrochloric acid gas from an absorber due to an earthquake. Hatamura Institute for the Advancement of Technology. Failure Knowledge Database: http://www.sozogaku.com/fkd/en/cfen/CC1000197.html 